\title{
NDD.02. Campaign of the world's stroke day in a country city of Ceará: experience report.
}

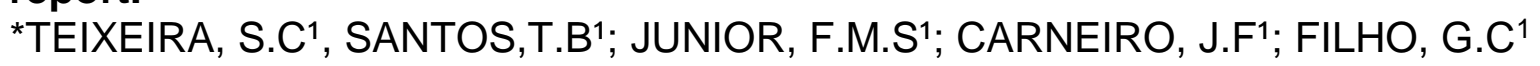

\author{
1 Universidade Federal do Ceará \\ 2Santa Casa de Misericórdia de Sobral \\ *suzanact@hotmail.com
}

Introduction: Stroke occurs suddenly at any age, sex or social class. It is the second leading cause of death in the world, responsible for 6 million deaths each year and the leading cause of disability due to the consequences that may leave. In Brazil and Ceará, stroke is the leading cause of death. Every 5 minutes a Brazilian dies from this disease, accounting for 100,000 deaths annually. An epidemiological study of the Integrated Care Program for stroke in the State of Ceará, with data collected since 2006 in 19 hospitals in Fortaleza states that are approximately 18,000 cases of stroke each year and about half of the cases are patients from the countryside. Within this number, about 4,500 people die. Therefore, the importance of the campaign " stroke ... I Care" which was held in a country city of Ceará by medical students on the same date to commemorate the World's Stroke Day. Besides focusing on risk factors, signs alert and emergency treatment of stroke, the campaign emphasized the importance of post stroke care, family, caregivers and associations to support patients. Objectives: This paper aims to describe the experiences of members of the Scientific Society of Neuroscience of Sobral during the educational campaign about stroke. Methods: On 26 October 2013, the campaign was held in a public place, one of the main squares of Sobral - Ceará where there is intense movement of people, with an educational and social aims. We carry out the delivery of flyers donated by Brazil Stroke Network and the World Stroke Campaign. Members of the Society for Neuroscience Sobral measured the blood pressure of popular. In addition, questionnaires were applied in order to assess the general knowledge of the population about stroke. Soon after, they were transferred about prevention, risk factors and early identification of the symptoms of stroke, as well as on how to proceed in this kind of situation. Discussion: Passersby were informed and asked to perform some basic behaviors in order to prevent stroke and to seek early medical assistance so identify early symptoms of stroke. Thus, to improve the quality of life in a joint action of public health informative and educational. Conclusions: The campaign against stroke was an important strategy of health education effective for increasing knowledge about this popular theme. There was great public interest by seeking clarifications and information, which contributed to the achievement of objectives, with the participation of hundreds of people. Thereby, helping to reduce the rates of stroke in Sobral.

TEIXEIRA, S.C.; SANTOS,T.B.; JUNIOR, F.M.S.; CARNEIRO, J.F.; FILHO, G.C. 2013. Campaign of the world's stroke day in a country city of Ceará: experience report, p.31. In: Oriá, Reinaldo Barreto; Andrade, Geanne Matos de; Bruin, Veralice Meireles S. de. I International Symposium in Neuroscience Meeting [Blucher Neuroscience Proceedings n.1 v.1]. São Paulo: Blucher, 2014, http://dx.doi.org/10.5151/isnm-sine26 